\title{
An Interview with a Leading Clinician-Scientist, Dr. Shawn Aaron
}

\author{
Rashi Raju Hiranandani ${ }^{* 1}$, Mohammad Ali Faraz ${ }^{* 1}$ \\ ${ }^{1}$ University of Ottawa, Faculty of Medicine, Ontario, Canada. *Equal contributors
}

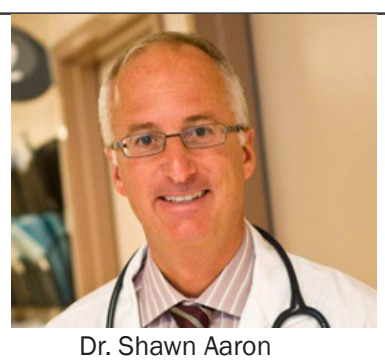

ABSTRACT

Dr. Shawn Aaron is a professor of medicine, senior scientist, principal investigator at the University of Ottawa, and the Chief of the Division of Respirology at The Ottawa General Hospital. He is also the Director of the Canadian Respiratory Research Network, a Canadian Institutes of Health Research (CIHR) Emerging Research Network. Dr. Aaron's clinical and research interests include chronic obstructive pulmonary disease (COPD), asthma, and cystic fibrosis (CF). We had the pleasure to speak with Dr. Aaron about his clinical and research experiences. He shared information about his medical, academic, and leadership roles. Finally, he also provided some advice for medical trainees in their path towards practicing medicine.

RÉSUMÉ

Dr. Shawn Aaron est un professeur de médecine, un scientifique chevronné et un chercheur principal à l'Université d'Ottawa, et le chef de la Division de pneumologie à l'Hôpital d'Ottawa. Il est également le directeur du Réseau canadien de recherche respiratoire, un réseau pour la recherche émergente des Instituts de recherche en santé du Canada (CIHR). Les champs d'intérêt cliniques et de recherche du Dr. Aaron incluent la maladie pulmonaire obstructive chronique (MPOC), l'asthme et la fibrose kystique (FK). Nous avons eu le plaisir de discuter avec Dr. Aaron au sujet de ses expériences cliniques et de recherche. Il a discuté de ses rôles médicaux, académiques et de leadership. Finalement, il a aussi offert quelques conseils pour les étudiants en médecine, en ce qui concerne leur cheminement vers la pratique médicale.

Could you tell us a bit about yourself and your academic background?

I completed my undergraduate and medical degrees at McGill, after which I did an Internal Medicine residency at the University of Toronto. I then pursued a combined Respirology and Critical Care fellowship, also at the University of Toronto. After that, I came to Ottawa and decided I wanted to do clinical research. I started my practice at the Ottawa Hospital and at the same time completed a Master's of Epidemiology at the University of Ottawa. The master's taught me how to perform research. I completed my master's when I was about 35-36 years old, at which point I officially became staff and an assistant professor at the University of Ottawa and started doing my own research.

How did you pick respirology as a career?

The thing I really loved about respirology was that you did not have to memorize anything. Everything could be figured out from going back to the first principles of medicine and physiology. I really liked the physiology and the fact that the lungs and breathing were logical and made sense when you thought of them. So that is why I chose respirology, because
I loved the fact you can figure things out without having to memorize!

Can you tell us about your roles as a clinician, researcher, professor and administrator and any other roles that you may have?

You are right. Right now, I do hold all of those roles. It can be challenging because you have to be doing a lot of different things in the same day. As you said, I am a clinician so I spend about $30 \%$ of my week seeing patients. The exception is that when I am on service, like I am now, I spend about $90 \%$ of the week seeing patients. The administration involves running the division and that is a big job; it takes about $20 \%$ of my time. I have to make sure that the division as a whole is meeting its clinical objectives, its educational objectives, and its research objectives. So there is a lot to take care of. We have to make sure we are providing good respiratory care to the citizens of the region, but we also have to make sure we are providing what the hospital needs, which is obviously a lot of service; a lot of taking care of patients within the hospital. We also have to make sure we are meeting the university requirements. This involves educating the students and the residents, and making

Keywords: Asthma; COPD; Cystic fibrosis 
sure the divisional members are producing quality research. The other $50 \%$ of my time is spent teaching and doing research. There is a lot we juggle, and if you are a young person you might think this is overwhelming, but my life is never boring; I am doing something different everyday. I love that part of my job. Everything is fresh, exciting, and fascinating. It never gets boring!

Considering that you are a very busy person, how do you manage your work-life balance?

It is easily managed because I just have to say that when I am at work, I am going to concentrate on my work. I work as hard as I can in order to be able to get everything done and go home at a decent time. I find that if you work hard and don't waste your time, you can get an awful lot done in a day and still get home at $6 \mathrm{pm}$. I am not superman nor am I smarter than anyone else. I come in to the hospital and start working as soon as I can. I also try to not get distracted; I don't go out for lunches during the daytime and I don't spend hours at the coffee shop. Also, I try not to bring my work home. It's not always easy, some nights I do have to work at home, but not most nights. Most nights, I get to spend time with my family and do other things that are important to me. So don't be discouraged, every doctor should be able to manage their work-life requirements assuming they work smart. Don't work longer, work harder.

Can you tell us a bit about your research in asthma?

The reason I chose these particular diseases (asthma, COPD, CF) to research is because they are chronic lung diseases that have devastating impacts on patients who suffer from them; I wanted to do things that could potentially improve their lives. I have had a really fun research career trying to do big studies to try to improve our care for these diseases. When I say big studies, I mean 700 patient studies where we try to answer an important question about the disease. One of the studies I am doing now, which I think might be important, is to examine how well people are being diagnosed with chronic lung disease in our communities. I get a lot of referrals to my clinic from family physicians because the patients are being referred for "asthma" and it turns out they do not have asthma, but they have something else. The question is: why are physicians sometimes over-diagnosing asthma or mistreating other diseases and calling them asthma? We are doing a big study right now to see what is happening across Canada. This was a study where we enrolled 700 patients across the country, from Halifax to Vancouver, who were recently diagnosed with asthma. We are testing the study participants to see if they actually have asthma, and if they do not we are linking them to a study respirologist to figure out what they actually have. These patients were randomly recruited from the community. There is a large minority that does not have asthma, more than $30 \%$, and some of them have very serious conditions that have gone misdiagnosed (1). So we are picking up people with very serious conditions who have been treated inappropriately with asthma medications when they should have been treated with something else. Ultimately, the aim is to try to improve care for everybody, while educating physicians across the country and the world to diagnose these conditions appropriately.

What recommendations would you make to physicians to appropriately diagnose asthma?

The most important thing is that asthma is a disease that causes typical symptoms such as shortness of breath, wheezing, and coughing. But the diagnosis can't be made without first confirming it with spirometry or a lung function test (the same goes for COPD). The problem is that in $50 \%$ of the cases in Canada, the disease is not being confirmed with these tests (2). The equivalent would be diagnosing diabetes and putting someone on insulin without measuring a blood sugar; that would never be done. We would never put someone on an hypertensive medicines without measuring their blood pressure. But for some reason in Canada, we are putting people on inhaled corticosteroids and other asthma medicines and labeling them as having asthma without ever testing their lung functions. It does not make any sense. So basically, the bottom line is that we should have objective measures, preferably before we make the diagnosis and start the treatment. It is not always easy, I understand that. But even if you can't get the tests before you treat, you should treat and then get the tests. So that is what I would advise doctors, let's start choosing wisely and doing the proper test in the proper context.

Could you tell us a bit about your research in CF?

One of the important questions that I have researched in the past and one of the important steps in CF management is to try to predict survival when the patient is getting so sick that they need to be referred for lung transplantation. As you could imagine, this is a very big and dangerous surgery that is not suggested until the patient is at the end stage of disease with an expected survival of less than 2 years. We are doing several 
studies now, trying to develop models to predict survival pre-transplant and also to predict survival for patients posttransplant. Our plan is to develop an online application for physicians and patients to use so that they can input their particular data into the application, such as their lung function, their sex, their genetics, and their bacteria, and then get the application to spit out the expected survival without lung transplantation and the expected survival if they go ahead with the transplant. This application would help the patients and physicians decide when is the appropriate time to go through this incredibly life-changing, dangerous surgery. So, that is one of the things I am working on trying to improve care for patients with cystic fibrosis with end stage, severe disease. I think in a year or two the application will become available for use by patients and physicians. It is all based on mathematical models of predicting survival in patients based on their current stage and we have done a lot of research on it. It is mathematics and statistics and it is lots of fun, particularly because it can be applied to help people and doctors make better decisions.

\section{Could you also tell us a bit about your research in COPD?}

Regarding COPD, I have done a lot of research in the past, way back in the dark ages when I did my master's degree in late 1990s and early 2000s. I started my master's thesis project at the University of Ottawa to determine whether prednisone was useful for COPD exacerbations. Believe it or not, back then we didn't have clinical data to show whether prednisone was useful in this context. So I designed a study in which patients who came to the Emergency Department (ED) were treated with either antibiotics and prednisone or antibiotics and placebo, to determine which group did better once discharged from the ED. The study started as my master's thesis with just about 25 patients. But then, because it was looking so interesting, I got a grant from the CIHR to do a bigger study which ended up growing to hundreds of patients, showing that prednisone with antibiotics clearly protected the patients with COPD exacerbations. The study ended up getting published in the New England Journal of Medicine (3), and it, along with those from other groups, provided the basis for how we practice medicine today (3-5). So for those of you in medical school, when you rotate through general medicine, family medicine, or emergency medicine, you will see that everybody who is admitted with, or goes home from the ED with COPD exacerbations is prescribed prednisone. Everybody thinks that of course we use prednisone, but twenty years ago this wasn't the case; we didn't know whether we should use this medication or not. So that's how you can change the face of medicine through research. In this way, you can impact patient care not only locally in your own practice, but globally, and that is incredibly exciting and rewarding.

As a respirologist, what public health measures would you suggest or hope to see for smoking cessation and prevention?

It is clear that smoking cessation and prevention are extremely important public health initiatives especially for lung diseases but even for cardiovascular diseases, cancer, and other illnesses. Smoking predisposes you to every cancer out there. Thus far, I think that we have done an excellent job in Canada to decrease smoking rates from $40 \%, 25$ years ago, to $16-18 \%$ now. I think what I would like to see is more strict control. If at all possible, my dream would be to see tobacco become illegal in this country. I don't know whether that will ever happen, but at the very least we can continue to spread the message to Canadians that tobacco is a dangerous product and we want to be limiting access to tobacco in any way that we can. For example, we should be using plain [cigarette] packaging. I don't think tobacco companies should ever be allowed to advertise or put pictures on their cigarette packages. Cigarettes should be packaged with a plain grey label, with a big warning that cigarettes cause lung cancers, emphysema, bladder cancers and the message has to keep on going to the young people. We have to keep educating young people on the evils of tobacco smoke and try to make smoking as uncool as possible. If we can show people that it is not attractive to smoke, we can keep young people from smoking. Also, we have to target the populations that are most at risk, because unfortunately those who tend to smoke are the people of lower socioeconomic status, people in some minority groups, and Aboriginal Canadians. We want to target those groups especially hard to try to convince them not to take up this habit.

As the final question, what advice would you give students who want to pursue a career in respirology?

Well, my advice would be that while respirology is a great field, they shouldn't necessarily pursue respirology and exclude other choices. Pursue what you are really interested in and what you think you are going to love. I think medicine right now is at an incredibly interesting me. The scientific and medical communities are developing amazing biological and molecular therapies to treat all sorts of chronic and acute diseases. So my advice is to do what you think is really going to interest you. The important thing is that you want to stay passionate about things and stay interested. My other bit of advice to young 
people is to get as much training as you can. Don't be afraid of the next residency, or the next research fellowship. Don't be afraid to start training in research, because an academic career where you do research and clinical work, as well as teach, is extremely desirable and interesting. So my advice to you is not to be afraid to challenge yourself. Go out and get advanced training in whatever field interests you, whether it is clinical, research, or education. Get as many years of education as you can, as much training as you can, because that makes you incredibly marketable for a job; you become interesting to other academic doctors if you have a master's degree, a PhD, a fellowship, or clinical training in some area, you become marketable and employable. And the other thing about the academic job that many people don't realize is that because of what you do, you get invited to give talks all over the world. I am not saying this to brag, but it can be exciting when you get to go to China to give a talk to the Chinese Respiratory Society and they pay for you to stay in a fancy hotel, and even take you out to a dinner! So, the bottom line is that you should have a job that will bring you joy, as well as keep you engaged and interested throughout a long career.

\section{ACKNOWLEDGEMENTS}

The authors would like to thank Dr. Aaron for taking his valuable time to answer all of our questions. He also helped edit the text in the article, and for that we thank him.

\section{REFERENCES}

1. Aaron SD, Vandemheen $K$, Boulet LP, et al. Over-diagnosis of asthma in obese and non-obese adults. CMAJ. 2008;179(11):1121-31.

2. Gershon A, Victor JC, Guan J, Aaron SD, To T. Pulmonary Function Testing in the Diagnosis of Asthma: A Population Study. Chest. 2012;141(5):1190-6

3. Aaron $S D$, Vandemheen $K$, Hebert $P$, et al. Outpatient oral prednisone after emergency treatment of chronic obstructive pulmonary disease. $\mathrm{N}$ Engl J Med. 2003;348(26):2618-25.

4. Sutherland ER, Chemiack RM. Management of Chronic Obstructive Pulmonary Disease. N Engl J Med. 2004;350(26):2689-97.

5. Halbert RJ, Natoli JL, Gano A, Badamgarav E, Buist AS, Mannino DM. Global burden of COPD: systematic review and meta-analysis. Eur Respir J. 2006;28(3):523-32. 